\title{
Conservation value of historical data: reconstructing stock dynamics of turbot during the last century in the Kattegat-Skagerrak
}

\author{
Massimiliano Cardinale ${ }^{1, *}$, Magdalena Linder ${ }^{1,2}$, Valerio Bartolino ${ }^{3}$, \\ Luigi Maiorano ${ }^{3}$, Michele Casini ${ }^{1}$ \\ ${ }^{1}$ Swedish Board of Fisheries, PO Box 4, Lysekil, Sweden \\ ${ }^{2}$ Department of Marine Ecology, Gothenburg University, Box 461, Gothenburg, Sweden \\ ${ }^{3}$ Department of Animal and Human Biology, University of Rome, La Sapienza, v.le dell'Universitá 32, 00185, Rome, Italy
}

\begin{abstract}
A quasi-complete time series of biomass, maximum body size and spatial distribution was reconstructed for turbot Psetta maxima L. in the Kattegat-Skagerrak based on standardized research surveys extending back to 1925 . Here we show that biomass has declined by about $86 \%$ over the time series, maximum body size has decreased by $20 \mathrm{~cm}$ and the northern component of the population has virtually vanished. These trends are likely to be underestimated due to the conservative approach we used by assuming a low level of 'technological creep' during the survey period, suggesting that the actual reduction in biomass might have been between 92 and $95 \%$. Absence of trend in former analyses of data collected in the last 2 or 3 decades is dangerously misleading. This substantial difference in stock status, based on historical data, highlights the general importance of the historical perspective for managing natural resources.
\end{abstract}

KEY WORDS: Historical population dynamics $\cdot$ Shifting baselines $\cdot$ Research data $\cdot$ Sustainability

\section{INTRODUCTION}

Ecologically sound management approaches and sustainable use of natural resources require a thorough understanding of the current status of those resources. Considering biological resources, such as fish stocks, many important aspects at the population level should be considered while framing management and/or conservation plans; these usually include stock productivity and resilience to exploitation in a fluctuating environment as well as consequences related to the socioeconomic impact of management measures (e.g. Fowler et al. 2005). Marine fish populations have been heavily exploited in most areas since at least the 1950s (Lotze \& Milewski 2004, Myers \& Worm 2005) and the current biodiversity crisis occurring in oceans worldwide is the obvious result of overexploitation and habitat degradation and destruction (Jackson et al. 2001, Ardizzone et al. 2006).
Most fishery management systems and almost all marine stock analyses are based on changes in population parameters as measured against an established baseline. Classical examples of these measures are trends in biomass, variations in the demographic structure of the population and changes in its spatial distribution (i.e. ICES 2007). To avoid an overly optimistic assessment of the conservation status of fish populations, a problem often referred to as the shifting baseline syndrome, these measures should be referred to a baseline of a relatively unfished (or unexploited) population, or at least a population only marginally exploited (Pauly 1995, Roberts 2007). The use of erroneous baselines can lead to erroneous assessments of stock status (Rose 2004) and ill-advised management strategies that could lead to stock depletion, collapse or even extirpation of entire populations (Hutchinson et al. 2003).

Even for biological systems for which long time series of data have been collected (e.g. many fish 
stocks in the North Atlantic; Rijnsdorp \& Millner, 1996, Rijnsdorp et al. 1996), conservation assessments are usually based on data and analyses covering the last few decades only (ICES 2007), and thus include populations that are far from pristine (Mackinson 2002, Engelhard 2008, Perdikaris \& McGovern 2008). A number of complex population models have been developed with the aim of improving population estimates and coping with the many sources of uncertainty (Sumaila 2001, Harwood \& Stokes 2003), but to really provide a better assessment of the conservation status of exploited species the available estimates should be re-evaluated using historical data, referring to populations before the onset of the industrial fishery exploitation (Lotze \& Milewski 2004, Myers \& Worm 2005).

We used the turbot Psetta maxima L. in the KattegatSkagerrak area as a case study to demonstrate the usefulness of historical data for assessing the conservation status of marine fish populations. The KattegatSkagerrak area connects the North Sea to the Baltic Sea and has not received as much research attention as other regions of the North Sea (Daan et al. 1996, Casini et al. 2005), especially considering the abundance, structure and distribution of the demersal fish populations distributed along the Swedish west coast (Støttrup et al. 2002, Svedäng 2003, Casini et al. 2005). In the North Sea, the turbot has been considered a highly prized fish (prime) since the middle of the 1800 s and historically has been exploited within a multi-species fishery targeting turbot, brill Scophthalmus rhombus and sole Sole solea (Mackinson 2002). In the KattegatSkagerrak, a semi-industrialized longline fishery targeting halibut, ling, cod, haddock and skate developed in the 1800s (Hasslöf 1949). During the late 1800s and early 1900s, trawling was introduced on a broad scale; this sector of the fleet was already larger than the longliners before the First World War (Andersson 1954). Unfortunately, no quantitative data exists on the development of the effective fishing effort in the area. Fish stocks at that time were considered lightly exploited compared to what has been observed in the last 3 decades (Roberts 2007, Sparholt et al. 2007). However, considering that a semi-industrialized fishery started at least a century before, the beginning of 1900s likely represents only a waypoint rather than a baseline from which it is possible to estimate the decline of fish populations in the North Sea (Garstang 1900, Roberts 2007).

Turbot is a species potentially vulnerable to fisheries due to its ecological (distributed mostly in coastal shallow areas; Curry-Lindahl 1985) and morphological (high gear vulnerability due to the particular body shape) characteristics. However, and despite its high commercial value and wide distribution (from the eastern Mediterranean to the North Sea), the stock status of turbot has not been assessed and it is not managed in the Kattegat-Skagerrak or in any other part of the North Sea. The Swedish Species Information Centre (www.artdata.slu.se/rodlista) classifies the turbot as near threatened, although no information is currently available in the literature about historical abundance or distribution trends of the species in the North Sea. Even though the species has been targeted since the beginning of the development of fisheries in the North Sea (mid-19th century; Robinson 1996), all previous analyses have considered at most the last 15 to $30 \mathrm{yr}^{\text {; Casini }}$ et al. (2005) analyzed the abundance of flatfish species in the Kattegat-Skagerrak during the period 1981-2003 and found no clear trend in the biomass of turbot, which was characterized by wide yearly fluctuations. Støttrup et al. (2002) also argued that turbot is not severely declining (since the 1990s) in the Kattegat-Skagerrak and, considering the last 2 decades of data, claimed that the species is not in need of any particular conservation measure.

Here we present standardized time series of population biomass, individual maximum size and spatial distribution of turbot based on research trawl survey data from the Swedish Institute of Marine Research. We provide the first historical time series analysis of turbot population dynamics in the North Sea dating back to the early part of the last century (1925 to 2007). Our results outline the potential risks associated to any assessment of marine fish stocks status based on short time series, especially in ecosystems historically affected by high anthropogenic pressures.

\section{MATERIALS AND METHODS}

Data. We compiled all known archived data from otter trawl surveys carried out in the Kattegat-Skaggerak (Fig. 1) from 1925 to 2007 by the Swedish Institute of Marine Research (Lysekil, Sweden) and its predecessors. These data are the result of a large project that started in Sweden in 2001 and aimed to collate all archived historical information concerning experimental trawls conducted by the Swedish authorities. This database incorporates a considerable number of different types of bottom trawls and 9 different research vessels, reflecting the numerous technological advances that occurred in the fishing industry since the early part of the last century. Since 1974, most surveys were conducted by the Swedish international RV 'Argos' within the International Bottom Trawl Survey (IBTS; ICES 1992), although national trawl surveys were also carried out (since 2000). For each trawl station the following information was available: date, haul duration, towing speed, setting and hauling position (latitude and longitude; prior to the use of a GPS those were reconstructed from detailed fishing area information 


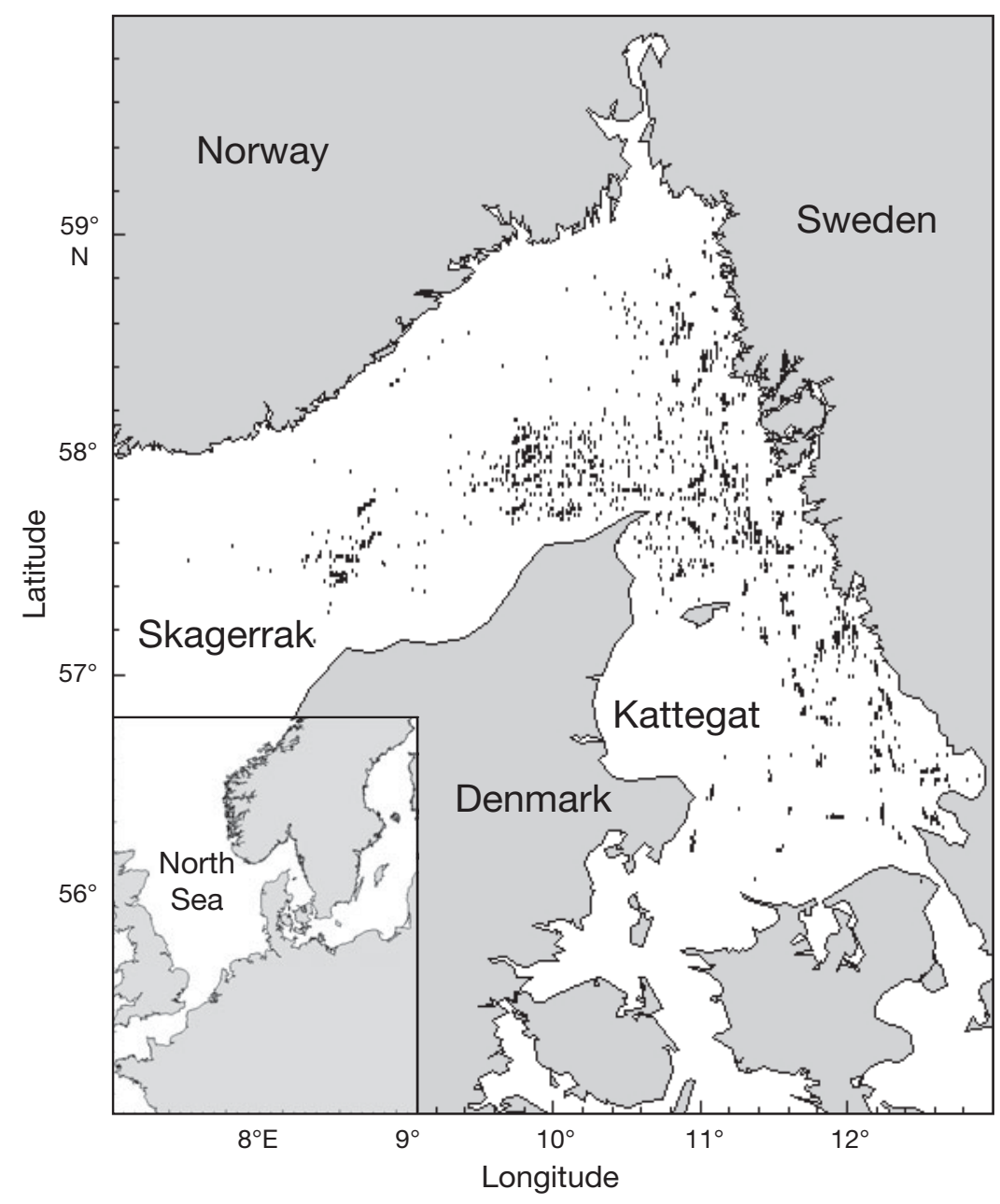

Fig. 1. Study area with location of the hauls (dots) conducted during the surveys and used in the analysis

included in the archived haul information) and depth. We included in the analyses only hauls carried out during daylight, and for each haul the total number of turbot caught and the total length of each individual were recorded. Further details of the survey database as well as standardization procedures and data analysis described below are available as supplementary material in 'Supplement 1' at www.int-res.com/articles/ suppl/m386p197_app.pdf.

Standardization of catch per unit effort (CPUE). The first step in standardizing CPUE values was to produce a bottom swept area abundance estimate for each haul (Rijnsdorp et al. 1996, Daan et al. 2005). Due to the different gear widths, tow times and tow speeds, we standardized each haul to a swept area of $0.89 \mathrm{~km}^{2}$. Such a procedure is usually defined as an area-swept abundance estimation (Harley \& Myers 2001) and in the present study it corresponds to the abundance of fish caught in $1 \mathrm{~h}$ trawling a swept area of $0.89 \mathrm{~km}^{2}$ (see 'Supplement 1' for details).
While standardization of the catches to swept areas largely improves CPUE comparability, it does not address gearspecific differences in selectivity (Knijn et al. 1993). CPUE information derived from different vessels, trawls and mesh sizes may be biased due to differences in the size at full selectivity, even if a single species is considered (Gunderson 1993, Knijn et al. 1993, Rijnsdorp et al. 1996, Harley \& Myers 2001). By restricting the analysis to length classes that can be considered fully selected by the largest mesh size included in the dataset (in our case length classes $>25 \mathrm{~cm}$ ), inconsistencies related to the gear selectivity are substantially reduced. We assume that above this size all individuals are equally vulnerable to the different gears used in the survey. Our standardization procedure minimizes the effect of different trawls and provides an acceptable compromise between the need for a robust comparison between years and the lack of complete information on trawl-specific catchability and selectivity. This procedure can also be used to reduce errors related to the different sampling strategies used from 1925 to 2007, with a bias against small fish that, especially in early surveys, might have been measured and reported less frequently than larger ones. Further details on the standardization procedure are available in Supplement 1.

Data analysis. Estimation of spawning stock biomass and average maximum length: In fish populations, trends in stock spawning biomass are representative of the reproductive potential of the stock as stock biomass is directly linked to the fecundity of the population (Hilborn \& Walters 1992). However, given that individual weights were not available in our database, to obtain haul-specific CPUE in biomass $\left(\mathrm{kg} \mathrm{h}^{-1}\right)$ and calculate an index of stock biomass for the turbot stock, we estimated individual fish weight $(W)$ from length $(L)$ measurements. Individual fish weights were estimated fitting a length-weight power relationship $\left(W=\mathrm{a} L^{\mathrm{b}}\right)$ on individual data collected between 1991 and 2007 in the Kattegat-Skagerrak $(\mathrm{a}=0.00001, \mathrm{~b}=3.1319, \mathrm{n}=89)$.

Yearly average maximum length $\left(L_{\max }\right.$ in $\left.\mathrm{cm}\right)$ was defined as the mean of the observed maximum length between hauls and was consequently not affected by haul standardization procedures. $L_{\max }$ is usually considered as a robust proxy for evaluating the conservation status of a fish population as it assumes that size 
reduction is due to intensified exploitation that removes the older and larger individuals (Piet \& Jennings 2005, Bailey et al. 2008).

Generalized additive model. To account for the unbalanced design in the sampling between year, month, latitude, longitude and depth, we used generalized additive models (GAMs; Hastie \& Tibshirani 1990) to model the haul-specific CPUE in biomass. In particular, to account for the large number of zero values in our data set (like most data sets in ecology and conservation; Martin et al. 2005), we used a quasi-Poisson distribution (Minami et al. 2007) to model CPUE with variance proportional to the mean and a log-link function to constrain the estimates to be positive. The quasi-likelihood approach assumes that the scale parameter of the distribution is unknown so that it could account for more over-dispersion than the classical Poisson distribution (Wood 2006).

Inspection of the distribution of $L_{\max }$ revealed that it was normally distributed. Accordingly, a second GAM was used to model $L_{\text {max }}$ using the normal distribution with a log-link function. Thus, the following full additive models were formulated respectively for CPUE and $L_{\max }$ :

$$
\begin{gathered}
\text { CPUE } \sim \beta_{1}+\mathrm{f}_{1}(\text { lat } \times \text { long })+\mathrm{f}_{2}(\text { lat } \times \text { year })+\mathrm{f}_{3}(\text { long } \times \\
\text { year })+\mathrm{f}_{4}(\text { year })+\mathrm{f}_{5}(\text { month })+\mathrm{f}_{6}(\text { depth })+\varepsilon \\
L_{\max } \sim \beta_{1}+\mathrm{f}_{1}(\text { lat } \times \text { long })+\mathrm{f}_{2}(\text { year })+\mathrm{f}_{3}(\text { month })+ \\
\mathrm{f}_{4}(\text { depth })+\varepsilon
\end{gathered}
$$

where $\beta_{1}$ is the intercept, $f_{i}$ are smoothing functions and $\varepsilon$ is a normally distributed error. We used isotropic smoothing (thin plate regression spline) to model the interaction between latitude and longitude as suggested by Wood (2006) and a cyclic cubic regression spline to smooth the month predictor because it forces the smoothing to have the same value and first few derivatives at its initial and final points. The interactions between year and latitude and year and longitude were modelled using a tensor product smoothing function as suggested by Wood (2006). This approach has been considered a good choice when product covariates have different unit scales and a different amount of smoothness is appropriate along the 2 axes (Wood 2006). All other predictors were modelled using the thin plate smoothing spline function (Wood 2004). The spatial temporal interactions for the CPUE model were included to allow for investigating changes in the spatial distribution of turbot during the long timeperiod analyzed. However, such a level of model complexity was not required in the $L_{\text {max }}$ model as it was only used for a temporal analysis and no mapping of $L_{\text {max }}$ was expected.

Several reduced models were tested excluding one or more covariates. Smoothing parameter estimation and model comparison was based on generalized cross validation (GCV; Wood 2001, 2003). GCV is a proxy for the model's out-of-sample predictive mean squared error. Therefore, a model with lower GCV has more explanatory power, and hence is preferred, compared to a model with higher GCV. Final models were selected based on the GCV criteria and the significance of the predictors fulfilled at the same time. A backward stepwise selection procedure was used by excluding the variable explaining the lowest amount of variance at each step. To simplify the interpretation of the results, the maximum number of knots was limited for the smooth term month and depth $(\mathrm{k}=4)$ and for the interaction between latitude and longitude $(\mathrm{k}=20)$. Residuals were analysed to inspect for homogeneity of variance and violation from normality assumptions and other anomalies in the data or in the model fit using graphical methods (Cleveland 1993). Considering the large data set used to fit the GAM (>4000 points), a sensitivity analysis was done to test the CPUE model stability with respect to the amount of information provided (see 'Supplement 1' for details).

Estimating yearly average $S S B$ and $L_{\max }$ values: The yearly average values of CPUE and $L_{\max }$ (with 1 st and 3th quartiles; Q1, Q3) were predicted from the respective final models. To estimate the year effect for CPUE, we calculated CPUE over the grid used for spatial mapping and converted $\mathrm{kg} \mathrm{h}^{-1}$ into $\mathrm{kg} \mathrm{km}^{-2}$ considering that $1 \mathrm{~h}$ of standard bottom swept area corresponded to $0.89 \mathrm{~km}^{2}$ (see 'Supplement 1' for how differences in net characteristics and towing speeds were accounted for). The estimates were then summed over the whole grid to get yearly biomass estimates over the entire area. It is important to consider that, as catchability is unknown and assumed constant for the entire time series, the calculated biomass is not representative of the total population biomass in the area but only of the relative trend during the time series. Estimation of the annual turbot biomass over the entire grid area represents an effective way to appropriately weight different areas, reconstruct trend biomass for the entire study period and extract the year effect from the model (Beare et al. 2005), also under spatial-temporal interactions (Maunder \& Punt 2004). The analysis was performed using the mgcv library of R (Wood 2001; www.r-project.org)

Mapping CPUE and reconstructing long-term trends in biomass and $L_{\text {max }}$ : The spatial distribution of CPUE was reconstructed, averaging over 10 yr time intervals using the estimates calculated during January to March for each point of the grid. We used the final model to obtain CPUE estimates over a regular grid of $0.5 \times 0.5 \mathrm{~km}$ (160 402 cells) that covered the KattegatSkagerrak area including the main fjords along the Swedish coast. Waters shallower than $5 \mathrm{~m}$ depth were 
excluded because no hauls were conducted below this depth (depth was measured with the data available through the Baltic GIS website, http://gis.ekoi.lt/gis/ index.php). A time series analysis was performed to describe the historical trends of $L_{\max }$. We estimated the values corresponding to missing years, interpolating the values from adjacent observations using a simple exponential smoothing function (Gardner 1985).

Accounting for changes in catchability: Like other indicators of stock abundance, CPUE relies on the assumption that catchability is constant over time. Unquestionably, this assumption does not hold if technological creeping and changes in fleet characteristics affect the catching efficiency of the fleet. Increasing catching efficiency (known also as technological creep or, simply, creep) of the fleet is usually positively related to the increase in skipper skills, investments in auxiliary equipment and more efficient gear and materials, replacement of old vessels by new ones and, to a lesser extent, upgraded engines (Rijnsdorp et al. 2006). Creep has been estimated to be around 1.6 to $2.8 \%$ per year for the beam trawl fishery targeting sole and plaice in the North Sea (Rijnsdorp et al. 2006), 0.6 to $3.1 \%$ for the prawn fisheries in Australia ( $\mathrm{O}^{\prime}$ Neill \& Leigh 2007) and up to $10 \%$ for Australian northern prawn fisheries (Ellis \& Wang 2006). Creep has been seldom estimated for surveys, although it is also known to occur in this case (Engelhard 2008). Marchal et al. (2003) estimated up to a $10 \%$ annual increase in catching efficiency for a survey in the North Sea. Creep in surveys is generally due to several factors, including improved efficiency of the gear due to enhanced materials, improved hydrodynamic performance of the trawl and better trawl contact with the bottom. These factors were not obviously accounted for in the swept area and GAM standardization; thus we corrected the long-term trend in CPUE estimates using a power function with an increase in catching efficiency of 1,2 and $3 \%$ per year. Creep was applied until 1974, when modern, fully standardized IBTS surveys began. From 1974 onwards, creep was considered null (but see Marchal et al. 2003).

\section{RESULTS}

\section{Changes in turbot abundance}

We considered a total of 4485 hauls covering $66 \mathrm{yr}$ during the period 1925-2007 (Fig. 1, Table S1, Supplement 1. All the predictors included in the final CPUE model were statistically significant with the predictors year, interaction between latitude and longitude and depth explaining the largest part of the deviance (Table 1). The final biomass model explained almost $38 \%$ of the total deviance (Table 2).
Relative biomass estimates assuming a technological creeping of $1 \%$ were used as a baseline scenario for describing historical trends. The effects of the significant univariate predictors included in the final models (month and depth) were plotted for a straightfor-

Table 1. Summary of all generalized additive models tested to select the final model to estimate catch per unit effort (CPUE) of stock biomass and average maximum body length $\left(L_{\max }\right)$ of turbot in the Kattegat-Skagerrak. Year, Month, Depth, Latitude, Longitude and the interaction between Latitude and Longitude (Lat:Long), Latitude and Year (Lat:Year) and Longitude and Year (Long:Year) are predictive factors included in the initial models. DEV: total deviance explained by the reduced models; GCV: proxy for the models out-ofsample predictive mean squared error; LED: predictors that explained the largest part of the model deviance

\begin{tabular}{|c|c|c|c|c|}
\hline $\mathrm{n}$ & Predictive factors & DEV & GCV & LED \\
\hline \multicolumn{5}{|c|}{ CPUE (>25 cm) } \\
\hline 1 & $\begin{array}{l}\text { Long:Lat, Lat:Year, Long:Year, } \\
\text { Lat, Long, Year, Month, Depth }\end{array}$ & 38.0 & 3.03 & $\begin{array}{l}\text { Long: } \\
\text { Lat,Year }\end{array}$ \\
\hline 2 & $\begin{array}{l}\text { Long:Lat, Lat:Year, Long:Year, } \\
\text { Lat, Long, Year, Month }\end{array}$ & 36.5 & 3.10 & \\
\hline 3 & $\begin{array}{l}\text { Long:Lat, Lat:Year, } \\
\text { Lat, Long, Year, Month }\end{array}$ & 32.3 & 3.29 & \\
\hline 4 & $\begin{array}{l}\text { Long:Lat, Lat:Year, } \\
\text { Lat, Year, Month }\end{array}$ & 31.1 & 3.33 & \\
\hline 5 & Long:Lat, Lat, Year, Month & 25.3 & 3.58 & \\
\hline \multicolumn{5}{|c|}{$\boldsymbol{L}_{\max }$} \\
\hline 1 & $\begin{array}{l}\text { Long:Lat, Lat, Long, } \\
\text { Year, Month, Depth }\end{array}$ & 38.1 & 58.4 & \\
\hline 2 & Long:Lat, Lat, Year, Month, Depth & 38.1 & 57.4 & \\
\hline 3 & Long:Lat, Year, Month, Depth & 35.7 & 59.3 & \\
\hline 4 & Long:Lat, Year, Depth & 35.6 & 59.2 & $\begin{array}{l}\text { Year, } \\
\text { Depth }\end{array}$ \\
\hline 5 & Year, Depth & 28.4 & 61.6 & \\
\hline
\end{tabular}

Table 2. Summary of final generalized additive models used to estimate catch per unit effort (CPUE) of stock biomass and average maximum body length $\left(L_{\max }\right)$ of turbot in the Kattegat-Skagerrak. n: no. of hauls used in the analysis; DEV: total deviance explained by the final models

\begin{tabular}{|c|c|c|c|}
\hline $\mathrm{df}$ & Variable & $F$ & $\mathrm{p}$ \\
\hline \multicolumn{4}{|c|}{ CPUE $(>25 \mathrm{~cm})(\mathrm{n}=4486, \mathrm{DEV}=38.0 \%)$} \\
\hline 8.9 & Year & 10.2 & $<0.0001$ \\
\hline 8.8 & Latitude & 25.3 & $<0.0001$ \\
\hline 8.9 & Longitude & 6.7 & $<0.0001$ \\
\hline 1.9 & Month & 38.3 & $<0.0001$ \\
\hline 1.8 & Depth & 6.8 & $<0.0005$ \\
\hline 16.5 & Lat:Year & 7.7 & $<0.0001$ \\
\hline 19.9 & Long:Year & 11.5 & $<0.0001$ \\
\hline 15.9 & Lat:Long & 12.1 & $<0.0001$ \\
\hline \multicolumn{4}{|c|}{$\boldsymbol{L}_{\max }(\mathrm{n}=427, \mathrm{DEV}=35.6 \%)$} \\
\hline 8.6 & Year & 10.1 & $<0.0001$ \\
\hline 2.1 & Depth & 4.3 & $<0.006$ \\
\hline 13.6 & Lat:Long & 2.1 & $<0.007$ \\
\hline
\end{tabular}


ward interpretation (Fig. S1, Supplement 1). Turbot was mainly caught during the winter in shallow areas (Fig. S1, Supplement 1). Fig. 2a represents the yearly average CPUE predicted by the final GAM model using only the observed data. Fig. $2 \mathrm{~b}$ shows the estimated biomass, relative to the value estimated in 1925, calculated by summing the model predictions over the entire area. The largest biomass level was observed at the beginning of the time series and it declined thereafter (Fig. 2a). After a small recovery at the end of the 1980s, turbot stock has fluctuated slightly during the 1990s and 2000s, remaining relatively stable since the mid-1990s. The decline in CPUE was about $86 \%$ of the maximum biomass of turbot observed at the beginning of the time series based on the first and last year of the time series. The decline is obviously more accentuated (between 90 and $95 \%$ ) if considering larger values of creep during the century (Fig. 2b).
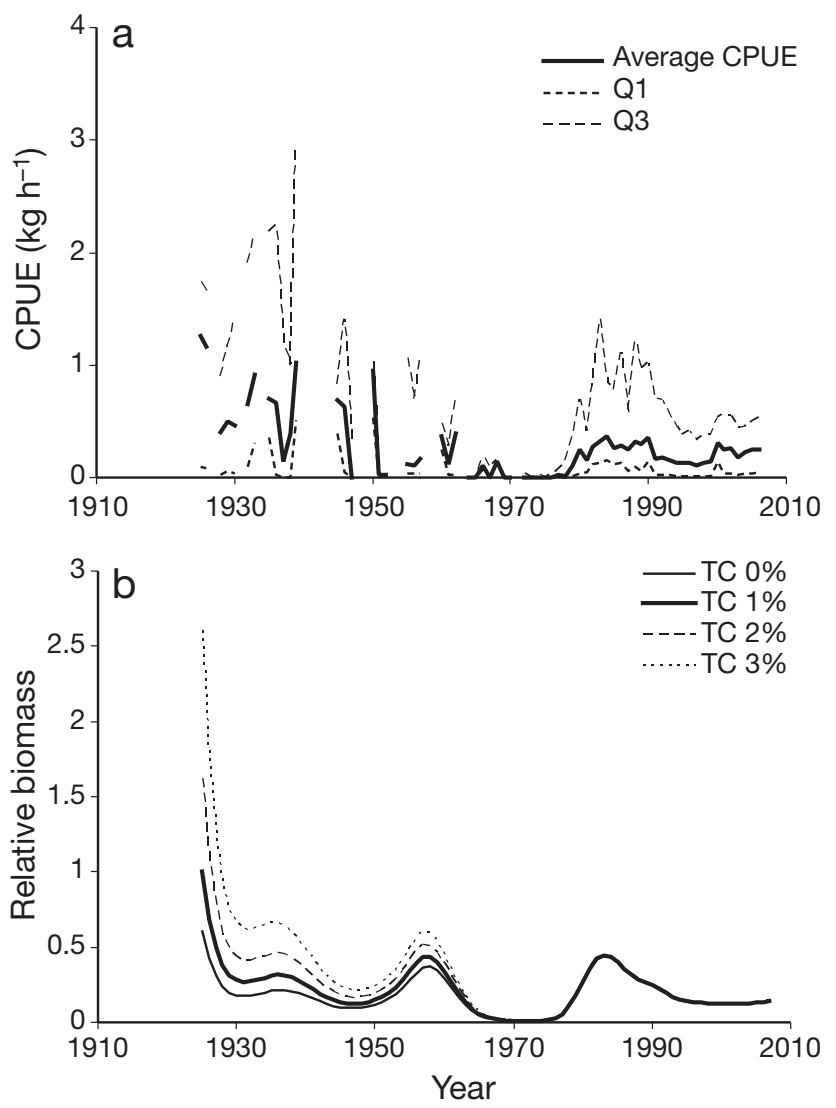

Fig. 2. (a) Estimated yearly CPUE ( $\mathrm{kg} \mathrm{h}^{-1}$; average, 1st [Q1] and 3rd quartiles [Q3]) predicted by the model using only the observed data. (b) Historical trend of the stock in terms of relative biomass compared to the value estimated in 1925 and assuming different levels of technological creep (TC). Stock biomass is calculated summing up CPUE predicted over the grid used for spatial mapping and converting $\mathrm{kg} \mathrm{h}^{-1}$ into $\mathrm{kg} \mathrm{km}^{-2}$ (see 'Mapping CPUE and reconstructing long-term tends in biomass and $L_{\max }$ ' for details)

\section{Changes in maximum average length}

Year, depth and the geographical coordinates were significant in the final maximum length model $\left(L_{\max }\right)$, with year accounting for the largest part of the deviance. The final model explained more than $35 \%$ of the total deviance (Table 1). A similar pattern as for CPUE was observed for $L_{\max }$ along the whole time period investigated. The largest value was observed at the beginning of the time series. From the mid-1950s, $L_{\max }$ declined rapidly until the late 1970 s and fluctuated afterwards around a constant value that was almost $20 \mathrm{~cm}$ less than the maximum observed length (Fig. 3a,b). The effects of the significant predictors included in the final models are plotted in Fig. S2, Supplement 1 . The largest fishes were caught at depths $>\sim 35 \mathrm{~m}$ (Fig. S2, Supplement 1).
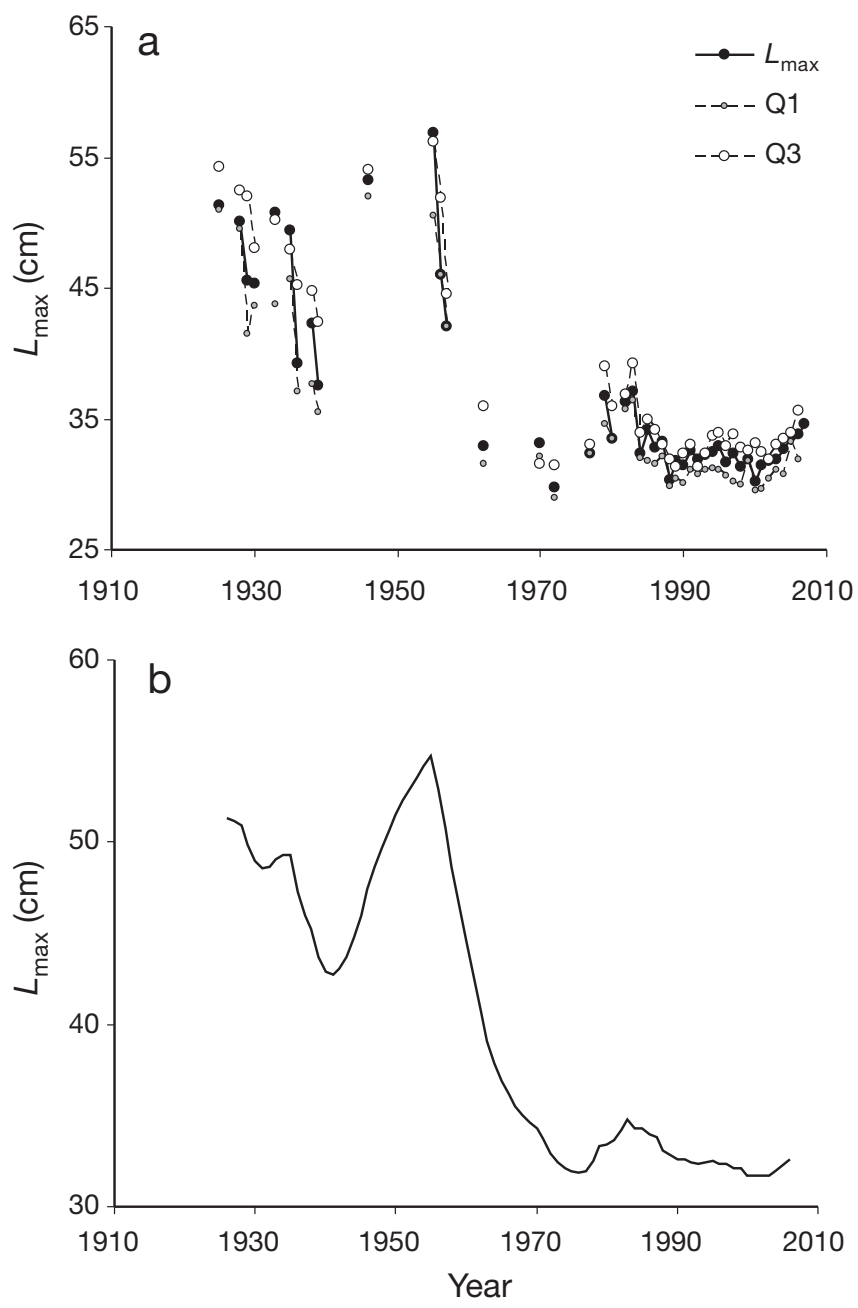

Fig. 3. (a) Historical trends in average maximum length $\left(L_{\max }\right.$ in $\mathrm{cm}$ ) of turbot (average, 1st [Q1] and 3th quartiles [Q3]). (b) Long-term trends in $L_{\max }$ after exponential smoothing (see 'Mapping CPUE and reconstructing long-term tends in biomass and $L_{\max }$ ' for details) 


\section{Changes in geographical distribution}

The effects of the variables that occurred in the models as multidimensional spatiotemporal smoothing (geographical position and year) were evaluated through time series maps (Fig. 4). Variations in geographical distribution and stock biomass characterize the time series maps with subsequent contraction and expansion of both distribution area and biomass, for example, during its historical minimum in the 1970 s (Fig. 4). In the $1920 \mathrm{~s}$, at the beginning of the time series, high densities of turbot were observed in many parts of the Kattegat-Skagerrak. These large aggregations declined from the 1930s to the 1950s when only a few hotspots were located offshore of the southeastern coasts of Denmark, the central and west coast of Sweden and in the fjord system (e.g. Gullmar and Hake fjords). Further decreases in the stock occurred from the 1950 s to 1970 s, when turbot densities were very low throughout almost the entire Kattegat-Skagerrak, with the exception of a small hotspot offshore of Denmark. Since the end of 20th century, the status of the turbot stock has slightly improved, especially in the southern part of the Kattegat-Skagerrat, where the highest concentrations can currently be located. However, the reductions to near-zero values of CPUE for the northern component of the stock suggests severe stock depletion in that area.
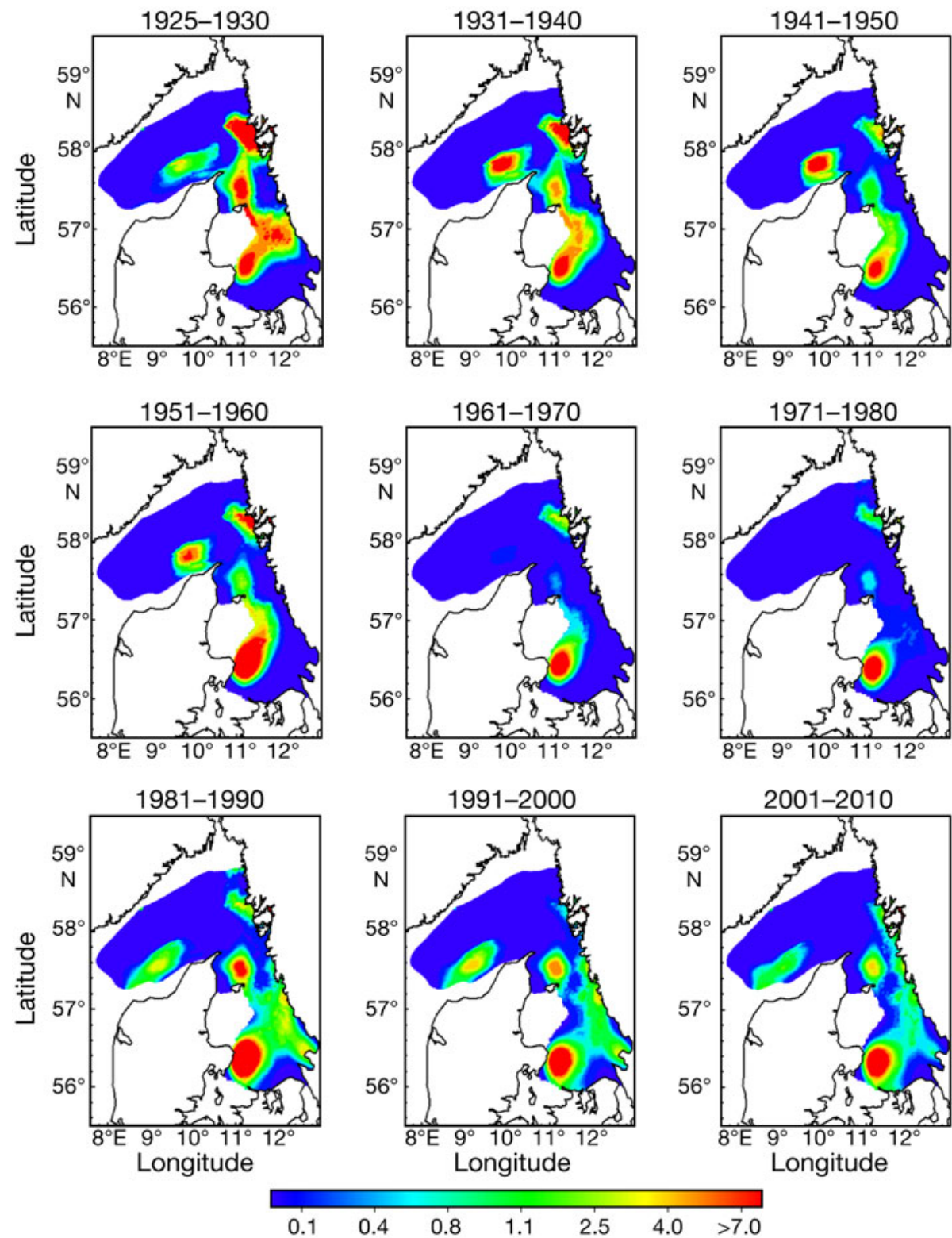

Fig. 4. Historical trends in spatial distribution of CPUE $\left(\mathrm{kg} \mathrm{h}^{-1}\right)$ and aggregation pattern of turbot in the Kattegat-Skagerrak (decadal average) estimated between January and March 


\section{DISCUSSION}

Our analyses are based on the assumption that the $83 \mathrm{yr}$ database used here can be analyzed without introducing serious biases into results. We based our analyses on the explicit inclusion of technological creeping, which provided a practical way of taking into account the paradigm shift in fisheries technology (Engelhard 2008). The effect of alternative technological creep values was tested, showing increasing reduction in the stock size in the second part of the time series (from 86 to $95 \%$ reduction in the estimated biomass) for increasing creep levels and clearly demonstrating that our conclusion would not have been influenced. We also performed a sensitivity analysis demonstrating that our results are fairly consistent and stable over increasingly smaller sample sizes, even with a $50 \%$ reduction in size of the data set considered, yielding confidence in its predictions. We were not able to completely solve all selectivity issues, such as the role of the catchability of different size classes that may vary with vessel speed or trawl type. Nevertheless, we consider our approach to provide estimates that are fairly robust with respect to amount of information, standardization procedures and underlying model assumptions, and therefore we are confident that our formulation is able to model an authentic signal from the data.

In the North Sea, turbot has been historically caught within a multispecies fishery targeting turbot, brill and sole (Mackinson 2002). These species were already considered as highly prized fish in the middle of the 1800s (Roberts 2007); despite this, little effort has been devoted to assess the conservation status of turbot in European waters. Blanchard et al. (2007) suggested that more than $30 \mathrm{yr}$ of survey data are necessary for detecting trends with high power (i.e. $>0.95$ ) for stocks which exhibit moderate patchiness and occur in periods of climate changes. Even though stock assessments based on 30 to $40 \mathrm{yr}$ of data are not uncommon (ICES 2007), only a very limited number of studies have considered a time span that goes back to or precedes the beginning of the industrial fisheries (e.g. Rijnsdorp \& Millner 1996, Rijnsdorp et al. 1996, Eero et al. 2008). Here we present such an analysis and also the first attempt at assessing trends of turbot for the North Sea using a reconstructed time series of biomass, maximum body size and spatial distribution based on standardized research surveys beginning in 1925 . We also show that a time series beginning only $30 \mathrm{yr}$ ago would have given erroneous values for estimating baseline levels of the turbot stock status in the Kattegat-Skagerrak. These results imply that having a historical perspective is fundamental for estimating management reference points to be used in restoration and long-term manage- ment of exploited fish populations. Our analysis thus provides a data-driven demonstration of the shifting baseline syndrome (Pauly 1995, Roberts 2007). SáenzArroyo et al. (2005) showed that this situation can potentially affect the stock assessment of vulnerable species by masking real population trends. The reduction of turbot in the study area before the massive fishery that occurred after the 1950s (Lotze \& Milewski 2004), which is usually considered the main cause of the decline of several stocks of demersal species, suggests instead that the pre-industrial fishery (Blegvad 1943) had already had a significant impact on the stock. An alternative interpretation is that the quality of the turbot nursery grounds has deteriorated due to pollution (in particular eutrophication) and increased frequency of hypoxia events occurring in the shallow sandy coastal waters of Denmark and Sweden (Pihl et al. 2005), affecting the productivity of the stock. As flatfish abundance appears to be determined during the nursery phase (Van der Veer et al. 2000), a decrease in the nursery habitat quality may reduce overall population abundance. However, the decline in biomass was also accompanied by a large decrease in average maximum length, with large individuals more abundant at the onset of the last century. One might argue that a decrease in maximum body size could also be an effect of environmental changes, such as a decrease in sea temperature or food availability that might affect growth rates (Maschner et al. 2008). However, we observed a decrease in mean size of the population during a period of general increasing temperature in the area (Rayner et al. 2003). Another explanation might be the expected changes in size selectivity due to changes in mesh size of the trawl. Nonetheless, the largest decline in $L_{\max }$ occurred much before (1950 to 1970) the use of the smallest mesh size (since 1973) and thus it is unlikely that this was the cause of the observed trend. Thus, the above considerations again corroborate the hypothesis that observed trends in length and stock size are a result of overexploitation.

This result provides important complementary information for a correct interpretation of the observed decreasing trend in the turbot stock biomass although no estimates of fishing mortality for turbot in the KattegatSkagerrak have been explicitly considered. Also, trends in both SSB and $L_{\max }$ seem to indicate that turbot declined strongly in the inter-war years, from high postWorld War I levels, while the stock recovered just after World War II, a phenomenon that was caused by the quasi-cessation of trawling activity during the wars (Wimpenny 1953). The decline then accelerated after the 1950s as also observed for other stocks in the North Sea (Holden 1978). Within this perspective, our findings strongly agree with the results from Christensen et al. (2003), who showed that the biomass of high-trophic 
level fish species in the North Atlantic declined by twothirds during the second half of the 20th century, and by a factor of around 9 for the century as a whole.

Our analyses clearly demonstrate that the lack of information from the pre-industrialized exploitation phase can potentially lead to misleading results with respect to the status of the stock being assessed and, consequently, to the possible implementation of illsuited fishery management strategies. In particular, the lack of clear trends in turbot population estimates in the last 30 yr does not imply that the stock is safely exploited and with no need of conservation measures. As reported by Casini et al. (2005), the turbot biomass dynamics over the last $25 \mathrm{yr}$ are mostly characterized by yearly fluctuations that are essentially uninformative about the real status of the stock. Prolonged exploitation significantly increases the probability for the stock to experience a roughly stable state at low quantities (Rose 2004) and, in some cases, a complete extinction (Hutchinson et al. 2003).

When viewed in a historical perspective it is clear that the turbot stock is likely to be largely overexploited and mainly constituted by relatively small individuals within a reduced geographical distribution area, a classical effect of overexploitation and a clear sign of a highly threatened status (Gaston et al. 2000). The substantial variation presented here in stock status over time indicates the importance of enforcing conservation measures to assure that the stock is not endangered (Waples et al. 2007) and can support a sustainable fishery in the future. Historical estimates therefore are important components of understanding the response of biological systems to exploitation and correctly evaluating the status of resources in humandominated ecosystems (Jackson et al. 2001, Rick \& Erlandson 2008). The limited information available from the pre-industrialized fishery exploitation phase is extremely informative and should be taken under much higher consideration within a framework of conservation and sustainable long-term exploitation of natural resources and ecosystems.

Acknowledgements. We thank 3 anonymous referees for their extremely constructive, careful and enthusiastic review of an original version of the manuscript.

\section{LITERATURE CITED}

Andersson KA (1954) Fiskar och Fiske I Norden. Bookförlaget Natur och Kultur, Stockholm

Ardizzone G, Belluscio A, Maiorano L (2006) Long-term change in the structure of a Posidonia oceanica landscape and its reference for a monitoring plan. PSZNI Mar Ecol 27:299-309

Bailey BG, Barrett J, Craig O, Milner N (2008) Historical ecology of the North Sea Basin: an archaeological perspective and some problems of methodology. In Rick TC, Erlandson JM (eds) Human impacts on ancient marine ecosystems: a global perspective. University of California Press, Berkeley and Los Angeles, CA, p 215-242

Beare DJ, Needle CL, Burns F, Reid DG (2005) Using survey data independently from commercial data in stock assessment: an example using haddock in ICES division VIa. ICES J Mar Sci 62:996-1005

Blanchard JL, Maxwell DL, Jennings S (2007) Power of monitoring surveys to detect abundance trends in depleted populations: the effect of density-dependent habitat use, patchiness and climate change. ICES J Mar Sci 65:111-120

Blegvad H (1943) Fiskeriet i Danmark. Selkabet for udgivelse af Kultutskrifter, Copenhagen

Casini M, Cardinale M, Hjelm J, Vitale F (2005) Trends in cpue and related changes in spatial distribution of demersal fish species in the Kattegat and Skagerrak, eastern North Sea, between 1981 and 2003. ICES J Mar Sci 62: 671-682

Christensen V, Guénette S, Heymans JJ, Walters CJ, Watson R, Zeller D, Pauly D (2003) Hundred-year decline of North Atlantic predatory fishes. Fish Fish 4:1-24

Cleveland WS (1993) Visualizing data. Hobart Press, Summit, NJ

Curry-Lindahl K (1985) Våra fiskar. Havs- och sötvattensfiskar i Norden och övriga Europa. PA Nordstedt \& Söner Förlag, Stockholm

Daan N, Richardson K, Pope JG (1996) Changes in the North Sea ecosystem and their causes: Aarhus revisited. ICES J Mar Sci 53:879-883

> Daan N, Gislason H, Pope JG, Rice J (2005) Changes in the North Sea fish community: Evidence of indirect effects of fishing? ICES J Mar Sci 62:177-188

Eero M, Friedrich W, Köster F, MacKenzie BR (2008) Reconstructing historical stock development of Atlantic cod (Gadus morhua) in the eastern Baltic Sea before the beginning of intensive exploitation. Can J Fish Aquat Sci 65:2728-2741

Ellis N, Wang YG (2006) Effects of fish density distribution and effort distribution on catchability. ICES J Mar Sci 64: 178-191

Engelhard H (2008) One hundred and twenty years of change in fishing power of English North Sea trawlers. In: Payne A, Cotter J, Potter T (eds) Advances in fisheries science: 50 years on from Beverton and Holt. Blackwell Publishing, Oxford, p 1-26

Fowler SL, Cavanagh RD, Camhl M, Burgess GH and others (2005) Sharks, rays and chimaeras: the status of the Chondrichthyan fishes. Status Survey. IUCN/SSC Shark Specialist Group. IUCN, Gland and Cambridge

Gardner ES Jr (1985) Exponential smoothing: the state of the art. J Forecast 4:1-28

Garstang W (1900) The impoverishment of the sea. J Mar Biol Assoc UK 6:1-69

> Gaston KJ, Blackburn TM, Greenwood JJD, Gregory RD, Quinn RM, Lawton JH (2000) Abundance-occupancy relationships. J Appl Ecol 37(Suppl):39-59

Gunderson DR (1993) Surveys of fisheries resources. Wiley \& Sons, New York

- Harley SJ, Myers RA (2001) Hierarchical Bayesian models of length-specific catchability of research trawl surveys. Can J Fish Aquat Sci 58:1569-1584

Harwood J, Stokes K (2003) Coping with uncertainty in ecological advice: lessons from fisheries. Trends Ecol Evol 18: $617-622$

Hasslöf O (1949) Svenska västkustfiskarna: Studier i en yrkesgrupps näringsliv och sociala kultur. Skrifter utgivna 
av bohusläns museum och Bohusläns hembygdsförbund, Nr 18. Risbergs tryckeri AB, Uddevalla

Hastie T, Tibshirani R (1990) Generalized additive models. Chapman \& Hall, London

Hilborn R, Walters CJ (1992) Quantitative fisheries stock assessment: choice, dynamics and uncertainty. Chapman \& Hall, New York

Holden MJ (1978) Long-term changes in landings of fish from the North Sea. Rapp P-V Reùn (Dan) 172:11-26

Hutchinson WF, van Oosterhout C, Rogers SI, Carvalho GR (2003) Temporal analysis of archived samples indicates marked genetic changes in declining North Sea cod (Gadus morhua). Proc R Soc Lond B Biol Sci 270:2125-2132

ICES (1992) Manual for international bottom trawl surveys, revision IV. ICES CM 1992/H:3/Addendum. ICES, Copenhagen

ICES (2008) Report of the ICES Advisory Committee, 2008. Book 6: North Sea. ICES Advice 2008. ICES, Copenhagen

Jackson JBC Kirby MX, Berger WH, Bjorndal KA and others (2001) Historical overfishing and the recent collapse of the coastal ecosystem. Science 293:629-638

Knijn RJ, Boon TW, Heessen HJL, Hinslop JRG (1993) Atlas of North Sea fishes. ICES Coop Res Rep 194:1-268

Lotze HK, Milewski L (2004) Two centuries of multiple human impacts and successive changes in a North Atlantic food web. Ecol Appl 14:1428-1447

Mackinson S (2002) Representing trophic interactions in the North Sea in the 1880s, using Ecopath mass-balance approach. In: Guénette S, Chistensen V, Pauly D (eds) Fisheries impacts on North Atlantic ecosystems: models and analyses. Fish Cent Res Rep 9:35-98

Marchal P, Ulrich C, Korsbrekke K, Pastoors M, Rackham B (2003) Annual trends in catchability and fish stock assessment. Sci Mar 67(Suppl):63-73

Martin TG, Wintle AB, Rhodes JR, Kuhnert PM and others (2005) Zero tolerance ecology: improving ecological inference by modeling the source of zero observations. Ecol Lett 8:1235-1246

Maschner HDG, Betts MW, Reedy-Maschner KL, Trites AW (2008) A 4500-year time series of Pacific cod (Gadus macrocephalus) size and abundance: archaeology, oceanic regime shifts, and sustainable fisheries. Fish Bull 106:386-394

Maunder MN, Punt AE (2004) Standardizing catch and effort data: a review of recent approaches. Fish Res 70:141-159

Minami M, Lennert-Cody CE, Gao W, Roman-Verdesoto M (2007) Modeling shark by-catch: the zero-inflated negative regression model with smoothing. Fish Res 84: 210-221

Myers RA, Worm B (2005) Rapid worldwide depletion of predatory fish communities. Nature 423:281-283

O'Neill MF, Leigh GM (2007) Fishing power increases continue in Queensland's east coast trawl fishery Australia. Fish Res 85:84-92

Pauly D (1995) Anecdotes and the shifting baseline syndrome of fisheries. Trends Ecol Evol 10:430

Perdikaris S, McGovern TH (2008) Codfish and kings, seals and subsistence. Norse marine resource use in the North Atlantic. In: Rick TC, Erlandson JM (eds) Human impact on ancient marine ecosystems: a global perspective. University of California Press, Berkeley and Los Angeles, CA, p $187-214$

Piet GJ, Jennings S (2005) Response of potential fish community indicators to fishing. ICES J Mar Sci 62:214-225

Pihl L, Modin J, Wennahage H (2005) Relating plaice (Pleuronectes platessa) recruitment to deteriorating habitat qual- ity: effects of macroalgal blooms in coastal nursery grounds. Can J Fish Aquat Sci 62:1184-1193

Rayner NA, Parker DE, Horton EB, Folland CK and others (2003) Global analyses of sea surface temperature, sea ice, and night marine air temperature since the late nineteenth century. J Geophys Res D 108:4407 doi:10.1029/ 2002JD002670.

Rick TC, Erlandson JM (2008) Human impact on ancient marine ecosystems: a global perspective. University of California Press, Berkeley and Los Angeles, CA

Rijnsdorp AD, Millner RS (1996) Trends in population dynamics and exploitation of North Sea plaice (Pleuronectes platessa L.) since the late 1800s. ICES J Mar Sci 53: $1170-1184$

Rijnsdorp AD, van Leeuwen PI, Daan N, Hessen HJL (1996) Changes in abundance of demersal fish species in the North Sea between 1906-1909 and 1990-1995. ICES J Mar Sci 53:1054-1062

Rijnsdorp AD, Daan N, Dekker W (2006) Partial fishing mortality per fishing trip: a useful indicator of effective fishing effort in mixed demersal fisheries. ICES J Mar Sci 63: $556-566$

Roberts C (2007) The unnatural history of the sea. Island Press, Washington, DC

Robinson R (1996) Trawling: the rise and fall of the British trawl fishery. University of Exeter Press, Exeter

Rose GA (2004) Reconciling overfishing and climate change with stock dynamics of Atlantic cod (Gadus morhua) over 500 years. Can J Fish Aquat Sci 61:1553-1557

- Sáenz-Arroyo A, Roberts CM, Torre M, Carino-Olvera M, Enriquez ARR (2005) Rapidly shifting environmental baselines among fishers of the Gulf of California. Proc R Soc Lond B Biol Sci 272:1957-1962

Sparholt H, Bertelsen M, Lassen H (2007) A meta-analysis of the status of ICES fish stocks during the past half century. ICES J Mar Sci 64:707-713

Støttrup JG, Sparrevohn CR, Modin J, Lehmann K (2002) The use of releases of reared fish to enhance natural populations: a case study of turbot Psetta maxima (Linné, 1758). Fish Res 59:161-180

Sumaila US (2001) Protected marine reserves as hedges against uncertainty: an economist's point of perspective. In: Pitcher TJ, Hart PJB, Pauly D (eds) Reinventing fisheries management. Fish and Fisheries Series 23, Kluwer Academic Publishers, Dordrecht, p 303-309

Svedäng H (2003) The inshore demersal fish community on the Swedish Skagerrak coast: regulation by recruitment from offshore sources. ICES J Mar Sci 60:23-31

Van der Veer HW, Berghahn RN, Miller JM, Rijnsdorp AD (2000) Recruitment in flatfish, with special emphasis on North Atlantic species: progress made by the flatfish symposia. ICES J Mar Sci 57:202-215

Waples RS, Adams PB, Bohnsack J, Taylor BL (2007) A biological framework for evaluating whether a species is threatened or endangered in a significant portion of its range. Conserv Biol 21:964-974

Wimpenny RS (1953) The plaice (being the Buckland Lectures for 1949). Edward Arnold, London

Wood SN (2001) mgcv: GAM and generalized ridge regression for R. R News 1/2:20-25

$>$ Wood SN (2004) Stable and efficient multiple smoothing parameter estimation for generalized additive models. J Am Stat Assoc 99:673-686

Wood SN (2006) Generalized additive models: an introduction with R. Chapman \& Hall/CRC, Boca Raton, FL 